\title{
Systemic monocyte chemoattractant protein-1 concentrations are independent of type 2 diabetes or parameters of obesity: results from the Cooperative Health Research in the Region of Augsburg Survey S4 (KORA S4)
}

Christian Herder, Sylvia Müller-Scholze, Philipp Rating, Wolfgang Koenig ${ }^{1}$, Barbara Thorand ${ }^{2}$, Burkhard Haastert ${ }^{3}$, Rolf Holle ${ }^{4}$, Thomas Illig ${ }^{2}$, Wolfgang Rathmann ${ }^{3}$, Jochen Seissler, H-Erich Wichmann ${ }^{2}$ and Hubert Kolb

German Diabetes Clinic, German Diabetes Centre, Leibniz Centre at Heinrich-Heine-University, Auf'm Hennekamp 65, 40225 Düsseldorf, Germany, ${ }^{1}$ Department of Internal Medicine II-Cardiology, Medical Centre, University of Ulm, Ulm, Germany, ${ }^{2}$ Institute of Epidemiology, GSF-National Research Centre for Environment and Health, Neuherberg, Germany, ${ }^{3}$ Institute of Biometrics and Epidemiology, German Diabetes Centre, Leibniz Centre at Heinrich-Heine-University, Düsseldorf, Germany and ${ }^{4}$ Institute of Health Economics and Health Care Management, GSF-National Research Centre for Environment and Health, Neuherberg, Germany

(Correspondence should be addressed to C Herder; Email: Christian.Herder@ddz.uni-duesseldorf.de)

\begin{abstract}
Objective: Data on the relevance of monocyte chemoattractant protein (MCP)-1 in the pathophysiology of type 2 diabetes (T2D) and obesity are inconsistent. Since MCP-1 is produced by adipocytes and has been postulated to be involved in macrophage infiltration into adipose tissue, we wanted to test whether serum MCP-1 levels were correlated with T2D or obesity.

Design and methods: Out of 1653 individuals aged 55 to 74 years participating in the population-based KORA Survey S4 (KORA/Cooperative Health Research in the Region of Augsburg) in Southern Germany, 236 patients with T2D, 242 subjects with impaired glucose tolerance and 244 normoglycaemic controls matched for age and sex were analysed for circulating MCP-1 concentrations.

Results: MCP-1 serum concentrations were not associated with impaired glucose tolerance, type 2 diabetes or several parameters of obesity. Moreover, systemic MCP-1 levels were not significantly correlated with all but one (fasting triglycerides) of the biochemical markers tested.

Conclusions: Our data indicate that MCP-1 levels are not associated with T2D and that the contribution of fat mass to systemic MCP-1 protein might be low, suggesting that the possible local pathogenic role of MCP-1 may not be reflected by increased systemic levels of MCP-1.
\end{abstract}

European Journal of Endocrinology $154311-317$

\section{Introduction}

Numerous reports have demonstrated an association of obesity and type 2 diabetes (T2D) with immunological parameters. Obese patients show small but definite increases in serum or plasma concentrations of acutephase proteins or proinflammatory cytokines such as C-reactive protein (CRP), interleukin (IL)-6, IL-18, or tumour necrosis factor (TNF) $\alpha$. Circulating levels of these immune mediators can be lowered by weight loss (1-4). Studies on T2D also clearly showed elevated systemic levels of acute-phase proteins including CRP, serum amyloid A, and fibrinogen, or of inflammationassociated cytokines such as IL-6. The possible relevance of these findings was underscored by observations that such immune abnormalities precede the diagnosis of T2D by several years (5-8). It has been hypothesised that such 'low-grade inflammation' is based on a mild but chronic activation of the innate immune system (9). The relative contribution of fat, and of adipocytes in particular, to systemic inflammation remains to be elucidated. Fat cells produce cytokines and chemokines such as IL-6 (10), TNF $\alpha$ (11), IL-8 (12) and MCP-1 (13) with broad biological activities, indicating a considerable overlap regarding immune mediator release between adipocytes and 'classical' cells of innate immunity such as monocytes/macrophages or endothelial cells (14). In addition, recent studies suggest that adipocytes may attract and activate macrophages resulting in an inflamed state of obese adipose tissue, i.e. in mouse models and in humans obesity was associated 
with infiltration of macrophages into adipose tissue (15-17). Obesity in mice was associated with significant upregulation of immune genes in adipose tissue including the chemokine monocyte chemoattractant protein (MCP)-1 $(15,16)$. It is therefore conceivable that adipocytes and macrophages participate in an intricate cellular network which forms during the development of obesity and which contributes to the pathophysiology of obesity-related complications like T2D and atherosclerosis. Chemokines such as MCP-1 are obvious candidates to induce macrophage infiltration into fat. Chemokines have been described as important components of innate immune reactivity. They represent a family of low molecular weight proteins that control leukocyte trafficking and activation and act as key mediators of inflammation and other pathophysiological states $(18,19)$. Studies using murine models of obesity indicate that MCP-1 is overexpressed in adipose tissue of obese mice leading to higher systemic MCP-1 concentrations (20, 21). At the cellular level, it seems that most of the MCP-1 secreted from adipose tissue is derived from non-fat cells (22-24). In different culture systems including 3T3L1 adipocytes, human in vitro differentiated adipocytes and whole tissue explants, it could be shown that MCP1 release could be stimulated with insulin resistanceassociated mediators such as TNF $\alpha$, IL-1 $\beta$, IL- 6 and growth hormone, whereas anti-diabetic/anti-inflammatory agents such as IL-10, metformin and thiazolidinediones suppressed MCP-1 release (13, 22, 24, 25). Insulin itself upregulated MCP-1 expression in 3T3-L1 adipocytes (25), but had no effect on MCP-1 release from adipose tissue in vitro (24). MCP-1 appears to affect adipocyte metabolism on multiple levels by decreasing lipid accumulation, protein tyrosine phosphorylation, expression of glucose transporter 4 and insulin-stimulated glucose uptake $(13,20)$. Thus, it is possible that elevated MCP-1 levels may have pathophysiological implications for the development of T2D. MCP-1 serum levels are elevated in patients with hypertension and dyslipidaemia (26), but reports on the association with T2D are inconsistent, and data from population-based studies are sparse $(27,28)$. We hypothesised that if MCP-1 is relevant for macrophage infiltration into adipose tissue and obesity-mediated immune activation, the analysis of circulating MCP-1 in participants of the KORA S4 should reveal a positive correlation of serum MCP-1 levels and diabetes status or parameters of obesity.

\section{Subjects and methods}

\section{Study population}

The design of the KORA Survey S4 (KORA S4, Kooperative Gesundheitsforschung in der Region Augsburg/ Cooperative Health Research in the Region of Augsburg; previously designated KORA Survey S2000) has been described previously (29). Briefly, a sample of the adult general population of German nationality in the region of Augsburg was recruited from October 1999 to April 2001. The sampling design followed the guidelines of three previous surveys conducted in this region within the frame of the multinational Monitoring of Trends and Determinants in Cardiovascular Disease (WHO-MONICA) Augsburg project (30). The investigations were carried out in accordance with the Declaration of Helsinki as revised in 1996, including written informed consent of all participants. The survey comprised 4261 men and women between 25 and 74 years of age, with a response rate of $67 \%$. Our report is based on subjects aged 55 to 74 years $(n=1653)$. All subjects participated in a standardised personal interview carried out by trained staff. Blood samples were obtained, which were fasting in non-diabetic subjects and in newly detected diabetic patients, and non-fasting in subjects with a known history of diabetes.

\section{Oral glucose tolerance test (OGTT)}

All individuals without a known history of diabetes were subjected to a $75 \mathrm{~g}$ OGTT. Because of the variability of OGTT $(31,32)$, a standardised protocol was followed which required fasting from $2200 \mathrm{~h}$ in the evening before the visit until 0800 to $1100 \mathrm{~h}$ the next day. Insulin resistance (IR) measured by homeostasis model assessment (HOMA) was calculated as follows: HOMA-IR = fasting glucose $(\mathrm{mmol} / \mathrm{l}) \times$ fasting insulin (mU/l)/22.5. Individuals with signs of infections were not eligible. Previously known diabetes was defined based on self-reported physician diagnosis or use of anti-diabetic agents. Newly diagnosed diabetes ( $\geq 7.0 \mathrm{mmol} / \mathrm{l}$ fasting or $\geq 11.1 \mathrm{mmol} / \mathrm{l} 2$-h glucose level), impaired glucose tolerance (IGT; 2-h glucose level $\geq 7.8 \mathrm{mmol} / \mathrm{l}$, but $<11.1 \mathrm{mmol} / \mathrm{l}$ ) and normal glucose tolerance were defined following the 1999 World Health Organization (WHO) criteria (33). Ten subjects were excluded because they were positive for glutamic acid decarboxylase (GAD) autoantibodies. Autoantibodies to GAD were measured using radiolabelled human recombinant antigen in a 96-well assay format as described (34). The cut-off for GAD antibody positivity was set at the 99th percentile in healthy control subjects (6.5 GAD antibody units). Furthermore, 4 subjects with an incorrect OGTT, 4 subjects with secondary diabetes because of pancreatitis and 5 subjects with known history of type 1 diabetes were excluded. Serum analyses were performed in individuals with T2D $(n=236)$, with IGT $(n=242)$ and in normoglycaemic control subjects $(n=244)$, frequency matched for age and sex. Diabetic patients comprised 116 individuals diagnosed previously with T2D by the treating physician (mean duration from diagnosis $9.1 \pm 6.7$ years) and 120 subjects with a diagnosis of T2D identified during the survey. 


\section{Bioelectrical impedance analysis and laboratory measurements}

Bioelectrical impedance analysis was conducted to estimate total fat-free mass and body fat using the BIA2000-S Analyser (Data Input, Frankfurt, Germany). Relevant parameters were estimated using the equation developed by Segal et al. (35). Blood samples were drawn and prepared according to the recommendations of the International Committee for Standardisation in Haematology (36). The following parameters were measured on fresh samples. Serum glucose was measured by Gluco-quant (hexokinase method; Roche Diagnostics, Mannheim, Germany). The percentage of HbAlc was analysed by Tina-quant (turbidimetric immunologic method; Roche Diagnostics). Total cholesterol was measured by enzymatic methods (CHOD-PAP; Roche Diagnostics). High-density lipoprotein (HDL) cholesterol was measured after precipitation with phosphotungstic acid/ $\mathrm{Mg}^{2+}$ (Roche Diagnostics), low-density lipoprotein (LDL) cholesterol after precipitation with dextran sulphate (Quantolip LDL; Immuno AG, Vienna, Austria). In addition, serum was stored at $-80{ }^{\circ} \mathrm{C}$ for further analyses.

\section{Analysis of CRP and MCP-1}

Plasma CRP concentrations were assessed by high sensitivity latex enhanced nephelometric assay on a BN II analyser (Dade Behring, Marburg, Germany) (37). Serum MCP-1 was measured by sandwich ELISA (R\&D Systems, Minneapolis, MN, USA), which met the following criteria: linearity of the signal for the standard curve between optical density 0.05 and 2.0, difference between expected and measured signal in spiking experiments less than $15 \%$, loss of signal after freezing and thawing of sera three times less than $20 \%$. Interference of heterophilic antibodies was not observed. Intra- and interassay variations were determined using serum samples assayed in duplicate in the same assay or in different assays. Mean values for intra- and interassay variations were $15.2 \%(n=79)$ and $16.9 \%(n=11)$ respectively. The detection limit was $17.8 \mathrm{pg} / \mathrm{ml}$. In one subject, the MCP-1 concentration was lower than the detection limit. This individual was assigned a value of $50 \%$ of the detection limit for further analyses.

\section{Statistical analyses}

Data with a Gaussian distribution were described by means \pm S.D., whereas data with a non-Gaussian distribution are given as median and 25 th $/ 75$ th percentiles (all other continuous variables). MCP-1 concentrations and log-transformed values were tested for normality with the Kolmogorov-Smirnov test. Differences between groups were analysed by $t$-test, Wilcoxon test, ANOVA and Kruskal-Wallis test, as appropriate.
In the case of 3-group comparisons, ANOVA combined with Fisher's Least Significant Difference test was used in the parametric case. In the non-parametric case the overall test of Kruskal-Wallis was followed by pairwise comparisons using Wilcoxon tests, if the overall test was significant. For dichotomous variables, absolute numbers were given and compared with the chisquare test. Spearman rank correlation coefficients were used to analyse associations between serum MCP-1 concentrations and clinical, metabolic or immunological variables. The level of significance was set at $P<0.05$. Calculations were carried out using GraphPad Prism 4 software (GraphPad Software, San Diego, CA, USA) and SAS Release 8.2 TS2MO (SAS Institute, Carg, NC, USA).

\section{Results}

\section{Basic characteristics of the study participants}

A comparison of basic characteristics of the study participants is given in Table 1 . The study group $(n=722)$ is slightly larger than the previously described group used for immunogenetic analyses $(n=704)$ (38). This difference is mainly due to missing DNA samples for some individuals, which were, however, included in the serological analysis. T2D, IGT and control groups were similar with regard to age and sex distribution. The patients with T2D or with IGT showed significantly elevated mean or median levels of body mass index (BMI), waist/hip ratio (WHR), body fat content, fasting glucose, fasting insulin, HOMA-IR, HbA1c, fasting triglycerides, systolic and diastolic blood pressure, CRP and leukocyte count compared with the normoglycaemic controls, while HDL cholesterol concentrations were lower than in controls (Table 1). In addition, patients with T2D exhibited a significantly elevated fat-free mass and decreased total and LDL cholesterol compared with controls (Table 1).

\section{Systemic MCP-1 concentrations are independent of diabetes status}

Both MCP-1 concentrations in the study participants and the corresponding log-transformed values differed significantly from a Gaussian distribution $(P<0.01)$, so that group comparisons regarding MCP-1 levels required non-parametric tests. MCP-1 serum concentrations did not differ significantly between patients with T2D, subjects with IGT and controls (median (25th; 75th percentiles): $286(214 ; 357) \mathrm{pg} / \mathrm{ml}$ vs 312 (229; 407) $\mathrm{pg} / \mathrm{ml}$ vs $311(214 ; 433) \mathrm{pg} / \mathrm{ml}$ respectively; $n=230 / 240 / 241 ; P=0.065$; Fig. 1 ). Exclusion of participants with a history of myocardial infarction (see Table 1) had hardly any impact on this result. Since anti-inflammatory medication or infections might modulate MCP-1 concentrations, all subjects on steroids, non-steroidal anti-inflammatory 
Table 1 Characteristics of the study population. Results are expressed as means \pm S.D. or median (25th; 75th percentiles). For dichotomous variables, absolute numbers are given.

\begin{tabular}{|c|c|c|c|}
\hline Variable & Normoglycaemic $(n=244)$ & IGT $(n=242)$ & T2D $(n=236)$ \\
\hline Sex (male/female) & $137 / 107$ & $130 / 112$ & $137 / 99$ \\
\hline Age (years) & $65.3 \pm 5.3(n=244)$ & $65.3 \pm 5.2(n=242)$ & $65.1 \pm 5.1(n=236)$ \\
\hline BMI $\left(\mathrm{kg} / \mathrm{m}^{2}\right)$ & $27.4 \pm 3.7(n=242)$ & $29.7 \pm 4.0^{\star \star \star}(n=241)$ & $30.9 \pm 4.5^{\star \star \star}(n=232)$ \\
\hline WHR & $0.90 \pm 0.08(n=243)$ & $0.92 \pm 0.07^{* *}(n=242)$ & $0.94 \pm 0.08^{* * *}(n=235)$ \\
\hline Body fat $(\mathrm{kg})$ & $27.3 \pm 6.6(n=238)$ & $30.7 \pm 6.9 * * *(n=240)$ & $32.8 \pm 8.4^{\star * *}(n=224)$ \\
\hline Body fat (\%) & $35.8 \pm 5.5(n=238)$ & $38.1 \pm 5.5^{\star \star \star}(n=240)$ & $38.6 \pm 5.9^{* \star *}(n=224)$ \\
\hline Fat-free mass (kg) & $48.7 \pm 8.7(n=238)$ & $49.8 \pm 8.1(n=240)$ & $51.7 \pm 8.6^{\star \star \star}(n=224)$ \\
\hline Fasting glucose ${ }^{\mathrm{a}}(\mathrm{mg} / \mathrm{dl})$ & $95(91 ; 101)(n=243)$ & $104^{* \star *}(98 ; 112)(n=240)$ & $128^{* * *}(114 ; 142)(n=118)$ \\
\hline Fasting insulin ${ }^{\mathrm{a}}(\mathrm{mU} / \mathrm{l})$ & $8.4(5.7 ; 12.2)(n=243)$ & $11.8^{* * *}(8.9 ; 17.3)(n=240)$ & $14.3^{* * *}(9.2 ; 21.2)(n=118)$ \\
\hline HOMA-IR ${ }^{\mathrm{a}}$ & $1.95(1.37 ; 2.99)(n=243)$ & $3.06^{\star \star \star}(2.20 ; 4.60)(n=240)$ & $4.54^{\star * *}(2.65 ; 7.61)(n=118)$ \\
\hline $\mathrm{HbA1c}(\%)$ & $5.6(5.3 ; 5.8)(n=244)$ & $5.6^{* \star}(5.4 ; 5.9)(n=242)$ & $6.4^{\star \star \star}(5.9 ; 7.2)(n=233)$ \\
\hline Total cholesterol (mg/dl) & $243 \pm 45(n=243)$ & $243 \pm 41(n=242)$ & $235 \pm 46 *(n=233)$ \\
\hline LDL cholesterol (mg/dl) & $155 \pm 43(n=242)$ & $156 \pm 38(n=242)$ & $145 \pm 41 *(n=232)$ \\
\hline HDL cholesterol (mg/dl) & $59 \pm 17(n=242)$ & $55 \pm 15^{\star}(n=242)$ & $50 \pm 14^{\star \star *}(n=233)$ \\
\hline Fasting triglycerides $^{\mathrm{a}}(\mathrm{mg} / \mathrm{dl})$ & $106(80 ; 144)(n=237)$ & $125^{\star \star *}(96 ; 174)(n=241)$ & $141^{\star \star \star *}(107 ; 196)(n=135)$ \\
\hline Systolic blood pressure ${ }^{\mathrm{b}}(\mathrm{mmHg})$ & $131 \pm 18(n=169)$ & $139 \pm 20^{* \star *}(n=118)$ & $146 \pm 21^{\star \star \star}(n=106)$ \\
\hline Diastolic blood pressure ${ }^{\mathrm{b}}(\mathrm{mmHg})$ & $78 \pm 10(n=169)$ & $81 \pm 9 *(n=118)$ & $84 \pm 11^{* * *}(n=106)$ \\
\hline Leukocyte count $\left(\times 10^{-3} / \mu \mathrm{l}\right)$ & $5.88 \pm 1.28(n=244)$ & $6.30 \pm 1.61^{\star *}(n=242)$ & $6.98 \pm 1.99^{\star \star *}(n=233)$ \\
\hline $\mathrm{CRP}(\mathrm{mg} / \mathrm{l})$ & $1.27(0.68 ; 2.98)(n=243)$ & $2.39^{\star \star \star}(1.25 ; 4.44)(n=241)$ & $2.52^{\star \star \star}(1.13 ; 5.63)(n=228)$ \\
\hline History of myocardial infarction (yes/no) & $16 / 228$ & $8 / 234$ & $16 / 220$ \\
\hline Recent infection ${ }^{\mathrm{C}}$ (yes/no) & $38 / 204$ & $41 / 198$ & $52 / 182$ \\
\hline Alcohol consumption (g/day) & $6.3(0.0 ; 25.7)(n=243)$ & $11.0(0.0 ; 24.5)(n=241)$ & $4.4(0.0 ; 22.0)(n=235)$ \\
\hline Smoking (yes/no) & $38 / 206$ & $26 / 216$ & $35 / 201$ \\
\hline
\end{tabular}

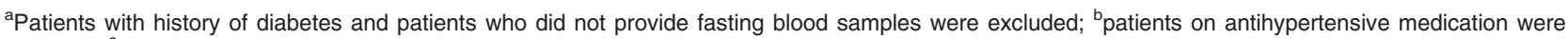
excluded; ' participants were asked for respiratory infections or other inflammatory conditions during the week prior to the examination.

${ }^{\star} P<0.05,{ }^{\star \star} P<0.01,{ }^{\star \star *} P<0.001$ compared with normoglycaemic controls.

agents, lipid-lowering drugs or hormone replacement therapy and subjects with recent infections were excluded in additional analyses. Results confirmed a lack of association of MCP-1 levels and diabetes status (T2D: 286 (207; 359) pg/ml vs IGT 302 (222; 408) $\mathrm{pg} / \mathrm{ml}$ vs controls $319 \quad(190 ; 451) \mathrm{pg} / \mathrm{ml}$; $n=121 / 118 / 121 ; P=0.34)$. Since the T2D group consisted of almost equal numbers of newly and previously diagnosed cases, these two subgroups were also compared. There was no statistically significant difference in MCP-1 levels between the two groups $(P=0.15)$.

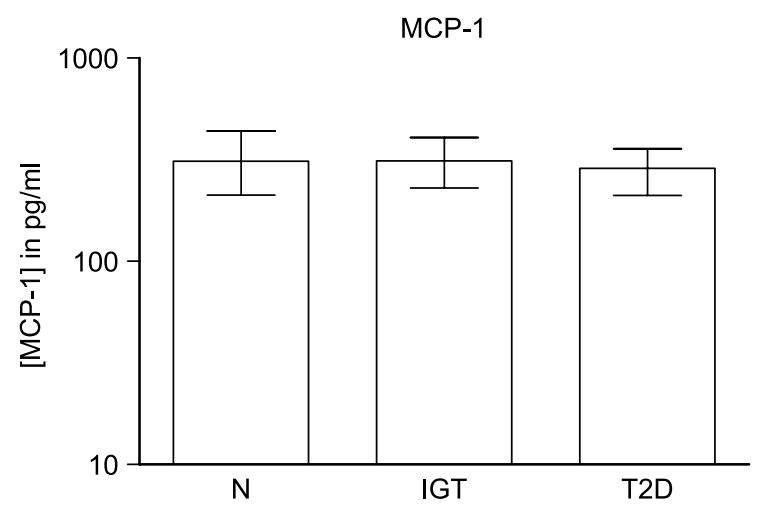

Figure $1 \mathrm{MCP}-1$ serum concentrations in patients with T2D $(n=241)$ or IGT $(n=240)$ and in normoglycaemic controls $(\mathrm{N} ; n=230)$ (results are given as median and 25th/75th percentiles) $P=0.065$ (Kruskal-Wallis test).

\section{Systemic MCP-1 concentrations are independent of obesity and other clinical or biochemical parameters}

In order to test for an association with clinical or biochemical markers including obesity-related variables, the whole study group was stratified into tertiles of MCP-1 serum concentrations. As shown in Table 2, study participants with low, intermediate or high MCP-1 levels did not differ statistically for any of the tested clinical or biochemical variables except for fasting triglyceride levels with a trend towards elevated triglycerides in individuals with high MCP-1 levels. This result was confirmed by Spearman rank correlation analysis, which included the whole study group and all variables shown in Table 2 . Serum MCP-1 concentrations were weakly correlated with fasting triglyceride levels $(r=0.09, P=0.03)$, but not significantly correlated with any of the other markers (data not shown).

\section{Discussion}

The aim of this study was to investigate the role of MCP-1 in the context of T2D and obesity. Our data demonstrate that circulating MCP-1 concentrations do not correlate significantly with IGT or T2D. The main strength of the KORA S4 is the representation of the population. This is especially important since MCP-1 has been described to be associated with components of the metabolic syndrome, but in particular 
Table 2 Clinical and biochemical variables of the study participants stratified for MCP-1 tertiles (described by median (25th; 75th percentiles) and range). Data with Gaussian or non-Gaussian distribution are given as means \pm S.D. and median (25th; 75th percentiles) respectively. For dichotomous variables, absolute numbers are given.

\begin{tabular}{|c|c|c|c|c|}
\hline Variable & $\begin{array}{c}\text { MCP-1 tertile 1 } \\
\text { (187.0 }(150.2 ; 220.3), \\
\text { range 8.9-247.8) }\end{array}$ & $\begin{array}{c}\text { MCP-1 tertile 2 } \\
\text { (300.1 (274.2; 329.4), } \\
\text { range 248.6-356.8) }\end{array}$ & $\begin{array}{c}\text { MCP-1 tertile 3 } \\
(450.0(397.8 ; 552.5), \\
\text { range 356.9-4877.0) }\end{array}$ & $P$ value \\
\hline Sex (male/female) & $133 / 104$ & $133 / 104$ & $133 / 104$ & NS (1.00) \\
\hline Age (years) & $65.1 \pm 5.2$ & $65.4 \pm 5.2$ & $65.2 \pm 5.3$ & NS (0.82) \\
\hline $\mathrm{BMI}\left(\mathrm{kg} / \mathrm{m}^{2}\right)$ & $29.3 \pm 4.3$ & $29.4 \pm 4.5$ & $29.0 \pm 4.1$ & NS (0.61) \\
\hline WHR & $0.91 \pm 0.08$ & $0.92 \pm 0.08$ & $0.92 \pm 0.07$ & NS (0.36) \\
\hline Body fat (kg) & $30.1 \pm 7.4$ & $30.4 \pm 8.2$ & $30.0 \pm 7.1$ & NS $(0.84)$ \\
\hline Body fat (\%) & $37.4 \pm 5.6$ & $37.4 \pm 5.9$ & $37.4 \pm 5.7$ & NS (1.00) \\
\hline Fat-free mass $(\mathrm{kg})$ & $49.9 \pm 8.4$ & $50.3 \pm 9.3$ & $49.8 \pm 8.0$ & NS (0.78) \\
\hline HOMA-IR ${ }^{a}$ & $2.50(1.68 ; 4.52)$ & $2.89(1.88 ; 4.46)$ & $2.78(1.76 ; 4.40)$ & NS $(0.38)$ \\
\hline $\mathrm{HbA1c}(\%)$ & $5.7(5.4 ; 6.1)$ & $5.7(5.5 ; 6.2)$ & $5.7(5.5 ; 6.0)$ & NS (0.26) \\
\hline Total cholesterol (mg/dl) & $239 \pm 43$ & $239 \pm 43$ & $244 \pm 45$ & NS (0.42) \\
\hline LDL cholesterol (mg/dl) & $154 \pm 40$ & $151 \pm 41$ & $152 \pm 43$ & NS (0.76) \\
\hline HDL cholesterol (mg/dl) & $55 \pm 15$ & $53 \pm 16$ & $56 \pm 16$ & NS $(0.22)$ \\
\hline Fasting triglycerides ${ }^{a}(\mathrm{mg} / \mathrm{dl})$ & $113(84 ; 153)$ & $125(96 ; 182)$ & $129(95 ; 169)$ & 0.01 \\
\hline Systolic blood pressure ${ }^{\mathrm{b}}(\mathrm{mmHg})$ & $135 \pm 22$ & $141 \pm 19$ & $138 \pm 19$ & NS (0.09) \\
\hline Diastolic blood pressure $^{\mathrm{b}}(\mathrm{mmHg})$ & $80 \pm 11$ & $81 \pm 11$ & $81 \pm 9$ & NS (0.31) \\
\hline Leukocyte count $\left(\times 10^{-3} / \mu \mathrm{l}\right)$ & $6.38 \pm 1.82$ & $6.31 \pm 1.62$ & $6.44 \pm 1.69$ & NS $(0.70)$ \\
\hline CRP (mg/l) & $1.90(0.96 ; 3.77)$ & $1.91(0.91 ; 4.20)$ & $2.16(1.02 ; 4.48)$ & NS (0.54) \\
\hline History of myocardial infarction (yes/no) & $12 / 225$ & $14 / 223$ & $12 / 225$ & NS (0.89) \\
\hline Recent infection ${ }^{\mathrm{c}}$ (yes/no) & $35 / 200$ & $54 / 180$ & $40 / 195$ & NS (0.06) \\
\hline Alcohol consumption (g/day) & $6.5(0.0 ; 22.9)$ & $5.7(0.0 ; 22.9)$ & $7.3(0.0 ; 27.0)$ & NS (0.40) \\
\hline Smoking (yes/no) & $24 / 213$ & $37 / 200$ & $38 / 199$ & NS $(0.12)$ \\
\hline
\end{tabular}

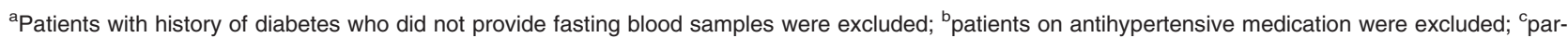
ticipants were asked for respiratory infections or other inflammatory conditions during the week prior to the examination.

NS, not significant.

with atherosclerosis (39). Any patient selection that leads to the accumulation of individuals with cardiovascular disease or risk factors like morbid obesity would therefore face the problem that the underlying atherosclerosis might significantly modify all MCP-1related associations. This may explain previous reports of elevated MCP-1 levels in patients with T2D or morbid obesity among patients with acute coronary syndromes $(40,41)$. It is conceivable that the combination of cardiovascular disease, T2D and/or morbid obesity increased MCP-1 levels by a mechanism which would not be detectable in a population without cardiovascular disease. This interpretation is supported by recent results from the Dallas Heart Study, which demonstrate the association between systemic MCP-1 concentrations and $\mathrm{T} 2 \mathrm{D}$ or $\mathrm{BMI}$ in the whole study population, whereas both associations disappeared after exclusion of all subjects with evidence of subclinical atherosclerosis (28). Since measures of subclinical atherosclerosis are not available for the KORA S4 participants, atherosclerosis cannot be excluded as confounder in the present study. It should, however, be noted that the diabetes and control groups, despite the difference in blood pressure, did not differ in the frequency of previous myocardial infarction. Hence, it is likely that the T2D patients in the KORA S4 had a lower cardiovascular burden than diabetes patients in the aforementioned studies where all patients had acute coronary symptoms $(40,41)$. A second factor that might explain the contrast with previous data may be the fact that most of the diabetes patients in KORA S4 were metabolically rather stable, as seen by the moderate differences between median $\mathrm{HbAlc}$ and fasting glucose levels that may have masked an effect of severe hyperglycaemia on systemic MCP-1 concentrations. The difference in fasting glucose levels between controls and previously undiagnosed T2D patients was higher in an Italian study of elderly women also selected from a population survey which indeed reported higher MCP-1 levels in T2D patients (27). This interpretation is supported by the recent observation that the MCP-1 mRNA expression in monocytes from poorly controlled T2D patients tended to be higher than in well-controlled T2D patients (42).

Despite the considerable number of study participants, we found no evidence that systemic MCP-1 concentrations are associated with parameters of obesity like BMI, WHR and body fat mass, indicating that the contribution of adipose tissue to circulating MCP-1 levels may be low. This observation is in line with other population-based surveys $(27,28)$. However, it has been reported that weight loss or exercise decrease systemic MCP-1 concentrations $(43,44)$. This effect may be attributable to a complex mechanism whereby weight loss and modest physical exercise lead to a general and systemic attenuation of low-grade inflammation which parallels weight loss and includes reduction of MCP-1 release from stromal-vascular cells accounting for most of the adipose tissue-derived MCP-1 (22-24). In this context, the population-based 
aspect of the survey might have been a disadvantage because a lean control group in the studied age group was not available. It cannot be excluded that a wider BMI range with higher proportions of lean and morbidly obese individuals would have revealed a positive association of MCP-1 levels and obesity-related variables. It should be noted that the study did reveal a significant positive association between systemic MCP-1 and elevated triglycerides levels, which are a feature of T2D and obesity. Since the association was relatively moderate (Spearman's rank coefficient $r=0.09$ ) and since we performed multiple tests in this study, a spurious association cannot be excluded.

Given the ever-increasing list of immunological mediators postulated to be risk factors or at least risk indicators for $\mathrm{T} 2 \mathrm{D}$, the lack of association between MCP-1 levels and IGT as well as T2D is remarkable. On the one hand, there is accumulating evidence that chronic low-grade activation of innate immunity is a major factor in the development of T2D $(8,9)$. On the other hand, this and other analyses of the immune status in epidemiological studies reveal that there is neither a general nor a random upregulation of inflammatory immune mediators, but rather a differential, specific and coordinated immune activation $(45,46)$.

In conclusion, we investigated the correlation of circulating MCP-1 levels with glucose tolerance status and indices of obesity. Our data demonstrate a lack of association of MCP-1 with IGT and T2D in the KORA Survey S4. In addition, MCP-1 concentrations were independent of various obesity-related parameters which suggests that at least in this elderly and mostly overweight or obese population, systemic MCP-1 levels are not significantly regulated by hyperglycaemia or adipose tissue mass and that the possible local pathogenic role of MCP-1 may not be reflected by increased systemic levels of MCP-1. These and previously published data highlight the need for large prospective studies in different populations to explore the contribution of elevated MCP-1 concentrations to the development of T2D.

\section{Acknowledgements}

The KORA research platform (KORA: Cooperative Health Research in the Region of Augsburg) was initiated and financed by the GSF - National Research Centre for Environment and Health, which is funded by the German Federal Ministry of Education and Research and by the State of Bavaria. The work was supported by the Deutsche Forschungsgemeinschaft, the European Foundation for the Study of Diabetes, the German Federal Ministry of Health and Social Security, the German Federal Ministry of Education, Science, Research and Technology, the Ministry of Science and Research of the State North Rhine-Westphalia and the Department of Internal Medicine II-Cardiology at the University of Ulm.

The KORA Survey S4 and, in particular, the diabetes substudy (OGTT) was coinitiated and co-financed by the German Diabetes Centre, Leibniz Centre for Diabetes Research at Heinrich-Heine-University, Düsseldorf, which is funded by the German Federal Ministry of Health and Social Security and the Ministry of Science and Research of the State North Rhine-Westphalia.

We thank Gabi Gornitzka, Petra Weskamp and Gerlinde Trischler for expert technical assistance and Drs W A Scherbaum and S Martin of the German Diabetes Centre for support. We are grateful to the KORA field team for conducting the data collection, and to Drs M Tietze and L Schindler (Central Laboratory of Central Clinics Augsburg, head Prof. Dr W Ehret) for blood biochemistry. We appreciate the voluntary contribution of all study participants.

\section{References}

1 Tchernof A, Nolan A, Sites CK, Ades PA \& Poehlman ET. Weight loss reduces C-reactive protein levels in obese postmenopausal women. Circulation 2002105 564-569.

2 Ziccardi P, Nappo F, Giugliano G, Esposito K, Marfella R, Cioffi M, D'Andrea F, Molinari AM \& Giugliano D. Reduction of inflammatory cytokine concentrations and improvement of endothelial functions in obese women after weight loss over one year. Circulation $2002105804-809$.

3 Esposito K, Pontillo A, Ciotola M, Di Palo C, Grella E, Nicoletti G \& Giugliano D. Weight loss reduces interleukin-18 levels in obese women. Journal of Clinical Endocrinology and Metabolism 2002 $873864-3866$.

4 Esposito K, Pontillo A, Di Palo C, Giugliano G, Masella M, Marfella R \& Giugliano D. Effect of weight loss and lifestyle changes on vascular inflammatory markers in obese women. Journal of the American Medical Association 2003289 1799-1804.

5 Pradhan AD, Manson JE, Rifai N, Buring JE \& Ridker PM. C-reactive protein, interleukin 6 , and risk of developing type 2 diabetes mellitus. Journal of the American Medical Association 2001286 327-334.

6 Festa A, D’Agostino R, Tracey RP \& Haffner SM. Elevated levels of acute-phase proteins and plasminogen activator inhibitor-1 predict the development of type 2 diabetes: the Insulin Resistance Atherosclerosis Study. Diabetes 200251 1131-1137.

7 Thorand B, Löwel H, Schneider A, Kolb H, Meisinger C, Fröhlich M $\&$ Koenig W. C-reactive protein as a predictor for incident diabetes mellitus among middle-aged men: results from the MONICA Augsburg cohort study, 1984-1998. Archives of Internal Medicine 2003163 93-99.

8 Kolb H \& Mandrup-Poulsen T. An immune origin of type 2 diabetes? Diabetologia $2005 \mathbf{4 8} 1038-1050$.

9 Pickup JC \& Crook MA. Is type II diabetes mellitus a disease of the innate immune system? Diabetologia 199841 1241-1248.

10 Mohamed-Ali V, Goodrick S, Rawesh A, Katz DR, Miles JM, Yudkin JS, Klein S \& Coppack SW. Subcutaneous adipose tissue releases interleukin-6, but not tumor necrosis factor- $\alpha$, in vivo. Journal of Clinical Endocrinology and Metabolism 199782 4196-4200.

11 Hotamisligil GS, Shargill NS \& Spiegelman BM. Adipose expression of tumor necrosis factor- $\alpha$ : direct role in obesitylinked insulin resistance. Science 1993259 87-91.

12 Bruun JM, Pedersen SB \& Richelsen B. Regulation of interleukin 8 production and gene expression in human adipose tissue in vitro. Journal of Clinical Endocrinology and Metabolism 200186 1267-1273.

13 Gerhardt CC, Romero IA, Cancello R, Camoin L \& Strosberg AD. Chemokines control fat accumulation and leptin secretion by cultured human adipocytes. Molecular and Cellular Endocrinology $200117581-92$.

14 Kershaw EE \& Flier JS. Adipose tissue as an endocrine organ. Journal of Clinical Endocrinology and Metabolism $2004892548-2556$. 
15 Weisberg SP, McCann D, Desai M, Rosenbaum M, Leibel RL \& Ferrante AW Jr. Obesity is associated with macrophage accumulation in adipose tissue. Journal of Clinical Investigation 2003 $1121796-1808$.

16 Xu H, Barnes GT, Yang Q, Tan G, Yang D, Chou CJ, Sole J, Nichols A, Ross JS, Tartaglia LA \& Chen H. Chronic inflammation in fat plays a crucial role in the development of obesity-related insulin resistance. Journal of Clinical Investigation 2003112 1821-1830.

17 Curat CA, Miranville A, Sengenes C, Diehl M, Tonus C, Busse R \& Bouloumie A. From blood monocytes to adipose-tissue-resident macrophages: induction of diapedesis by human mature adipocytes. Diabetes 200453 1285-1292.

18 Baggiolini M, Dewald B \& Moser B. Human chemokines: an update. Annual Review of Immunology 199715 675-705.

19 Gerard C \& Rollins BJ. Chemokines and disease. Nature Immunology 20012 108-115.

20 Sartipy P \& Loskutoff DJ. Monocyte chemoattractant protein 1 in obesity and insulin resistance. PNAS 2003100 7265-7270.

21 Takahashi K, Mizuarai S, Araki H, Mashiko S, Ishihara A, Kanatani A, Itadani H \& Kotani H. Adiposity elevates plasma MCP-1 levels leading to the increased CD11b-positive monocytes in mice. Journal of Biological Chemistry $20034746654-46660$.

22 Bruun JM, Lihn AS, Pedersen SB \& Richelsen B. Monocyte chemoattractant protein-1 release is higher in visceral than subcutaneous human adipose tissue (AT) implications of macrophages resident in the AT. Journal of Clinical Endocrinology and Metabolism $2005902282-2289$.

23 Di Gregorio GB, Yao-Borengasser A, Rasouli N, Varma V, Lu T, Miles LM, Ranganathan G, Peterson CA, McGehee RE \& Kern PA. Expression of CD68 and macrophage chemoattractant protein-1 genes in human adipose and muscle tissues: association with cytokine expression, insulin resistance, and reduction by pioglitazone. Diabetes $2005 \mathbf{5 4} 2305-2313$.

24 Fain JN \& Madan AK. Regulation of monocyte chemoattractant protein 1 (MCP-1) release by explants of human visceral adipose tissue. International Journal of Obesity and Related Metabolic Disorders 200529 1299-1307.

25 Fasshauer M, Klein J, Kralisch S, Klier M, Lossner U, Bluher M \& Paschke R. Monocyte chemoattractant protein 1 expression is stimulated by growth hormone and interleukin-6 in 3T3-L1 adipocytes. Biochemical and Biophysical Research Communications $2004317598-604$.

26 Parissis JT, Venetsanou KF, Kalantzi MV, Mentzikof DD \& Karas SM. Serum profiles of granulocyte-macrophage colony-stimulating factor and $\mathrm{C}-\mathrm{C}$ chemokines in hypertensive patients with or without significant hyperlipidemia. American Journal of Cardiology $200285777-779$.

27 Piemonti L, Calori G, Mercalli A, Lattuada G, Monti P, Garancini MP, Costantino F, Ruotolo G, Luzi L \& Perseghin G. Fasting plasma leptin, tumor necrosis factor- $\alpha$ receptor 2 , and monocyte chemoattracting protein-1 concentration in a population of glucose-tolerant and glucose-intolerant women. Diabetes Care $2003262883-2889$.

28 Deo R, Khera A, McGuire DK, Murphy SA, Meo Neto JP, Morrow DA \& de Lemos JA. Association among plasma levels of monocyte chemoattractant protein-1, traditional cardiovascular risk factors, and subclinical atherosclerosis. Journal of the American College of Cardiology $2004 \mathbf{4 4} 1812-1818$.

29 Rathmann W, Haastert B, Icks A, Löwel H, Meisinger C, Holle R \& Giani G. High prevalence of undiagnosed diabetes mellitus in Southern Germany: target populations for efficient screening. The KORA survey 2000. Diabetologia $2003 \mathbf{4 6} 182-189$.

30 Hense HW, Filipiak B, Doring A, Stieber J, Liese A \& Keil U. Ten-year trends of cardiovascular risk factors in the MONICA Augsburg region in Southern Germany. Results from the 1984/85, 1989/90 and 1994/95 survey. CVD Prevention $19981318-327$.

31 Stolk RP, Orchard TJ \& Grobbee DE. Why use the oral glucose tolerance test? Diabetes Care 199518 1045-1049.

32 Mooy JM, Grootenhuis PA, de Vries H, Kostense PJ, PoppSnijders C, Bouter LM \& Heine RJ. Intra-individual variation of glucose, specific insulin and proinsulin concentrations measured by two oral glucose tolerance tests in a general Caucasian population: the Hoorn Study. Diabetologia 199639 298-305.

33 World Health Organisation. Definition, diagnosis and classification of diabetes mellitus and its complications. Part 1: diagnosis and classification of diabetes mellitus. Report of a WHO consultation. WHO, Geneva, 1999.

34 Seissler J, Morgenthaler NG, Achenbach P, Lampeter EF, Glawe D, Payton M, Christie M \& Scherbaum WA. Combined screening for autoantibodies to IA-2 and antibodies to glutamic acid decarboxylase in first degree relatives of patients with IDDM. The DENIS Study Group. Deutsche Nikotinamid Interventions-Studie. Diabetologia $1996391351-1356$.

35 Segal KR, Van Loan M, Fitzgerald PI, Hodgdon JA \& Van Itallie TB. Lean body mass estimation by bioelectrical impedance analysis: a four-site cross-validation study. American Journal of Clinical Nutrition $1988 \mathbf{4 7} 7-14$.

36 International Committee for Standardization in Haematology. Recommendation for a selected method for the measurement of plasma viscosity. Journal of Clinical Pathology 199437 1147-1152.

37 Rifai N, Tracy RP \& Ridker PM. Clinical efficacy of an automated high-sensitivity C-reactive protein assay. Clinical Chemistry 1999 45 2136-2141.

38 Illig T, Bongardt F, Schopfer A, Muller-Scholze S, Rathmann W, Koenig W, Thorand B, Vollmert C, Holle R, Kolb H \& Herder C. Kooperative Gesundheitsforschung im Raum Augsburg/Cooperative Research in the Region of Augsburg. Significant association of the interleukin-6 gene polymorphisms C174G and A-598G with type 2 diabetes. Journal of Clinical Endocrinology and Metabolism $2004895053-5058$.

39 Libby P. Inflammation in atherosclerosis. Nature $2002 \mathbf{4 2 0}$ $868-874$.

40 Simeoni E, Hoffmann MM, Winkelmann BR, Ruiz J, Fleury S, Boehm BO, Marz W \& Vassalli G. Association between the A-2518G polymorphism in the monocyte chemoattractant protein-1 gene and insulin resistance and type 2 diabetes mellitus. Diabetologia $2004 \mathbf{4 7} 1574-1580$.

41 de Lemos JA, Morrow DA, Sabatine MS, Murphy SA, Gibson CM, Antman EM, McCabe CH, Cannon CP \& Braunwald E. Association between plasma levels of monocyte chemoattractant protein-1 and long-term clinical outcomes in patients with acute coronary syndromes. Circulation $2003 \mathbf{1 0 7} 690-695$.

42 Cipolletta C, Ryan KE, Hanna EV \& Trimble ER. Activation of peripheral blood CD14 + monocytes occurs in diabetes. Diabetes $2005542779-2786$.

43 Troseid M, Lappegard KT, Claudi T, Damas JK, Morkrid L, Brendberg R \& Mollnes TE. Exercise reduces plasma levels of the chemokines MCP-1 and IL-8 in subjects with the metabolic syndrome. European Heart Journal 200425349.

44 Christiansen T, Richelsen B \& Bruun JM. Monocyte chemoattractant protein-1 is produced in isolated adipocytes, associated with adiposity and reduced after weight loss in morbid obese subjects. International Journal of Obesity and Related Metabolic Disorders $200529146-150$.

45 Muller S, Martin S, Koenig W, Hanifi-Moghaddam P, Rathmann W, Haastert B, Giani G, Illig T, Thorand B \& Kolb H. Impaired glucose tolerance is associated with increased serum concentrations of interleukin 6 and co-regulated acute-phase proteins but not TNF-alpha or its receptors. Diabetologia 200245 805-812.

46 Herder C, Haastert B, Müller-Scholze S, Koenig W, Thorand B, Holle R, Wichmann HE, Scherbaum WA, Martin S \& Kolb H. Association of Systemic chemokine concentrations with impaired glucose tolerance and type 2 diabetes. Results from the cooperative Health Research in the Region of Augsburg Survey S4 (KORA S4). Diabetes $2005 \mathbf{5 4}$ S11-S17.

Received 18 July 2005

Accepted 10 November 2005 